\title{
A Survey of large and medium-sized mammals in Wabe forest fragments, Gurage zone, Ethiopia
}

\begin{abstract}
Mammal inventories are essential tools to effectively direct conservation strategies and management practices. A survey of large and medium -sized mammals was conducted in Wabe Forest fragments near to Wolkite town of Ethiopia to assess their diversity and abundance in the area and to determine their major threats. Transect method and anecdotal interviews were used to collect data for the study. A total of 12 mammal species belonging to seven orders and seven families were recorded by direct and indirect evidences. Porcupine (Hystrix cristata), honey badger (Mellivera capensis), vervet monkey (Chlorocebus aethiops), olive baboon (Papio anubis), and colobus guereza (Colobus guereza) were among the medium-sized mammals, and spotted hyena (Crocuta crocuta), aardvark (Oryctropus afer), bohor reedbuck (Redunca redunca), Oribi (Ourebia ourebi) and common duiker (Sylvicapra grimmia) were the large mammals of the study area. Vervet monkey (C. aethiops) was the dominant species followed by guereza (Colobus guereza), whereas common duiker (S . grimmia), spotted hyena (C. crocuta) and bush pig (Pontamochoreus larvatus) were less common. Mammals were recorded in low population number in the study area. Simpson's Similarity Index (SI) showed a considerable overlap of species between the natural forest and scrubland habitats $(0.58 \%)$ with reference to species composition. Field observation and interviews indicated illegal logging of trees for fuel wood and charcoal production, domestic dogs, road construction and extraction of construction materials, and agricultural land expansion were the main anthropogenic threats in the area. The study area harbors considerable mammals that are threatened by interacting anthropogenic factors. Urgent conservation program is needed to safeguard these animals.
\end{abstract}

Keywords: abundance, anthropogenic factors, conservation, diversity, ethiopia, mammals, wabe forest fragment

\section{Introduction}

Mammals are an important ecological constituent of terrestrial ecosystems. ${ }^{1}$ Large-sized mammals (weigh more than $7 \mathrm{~kg}$ ) and medium-sized mammals (weigh between 2 and $7 \mathrm{~kg}$ ), ${ }^{2}$ in particular have important ecosystem functions. ${ }^{3}$ They regulate plant diversity and structure and potential pest species through hervibory, other animal populations through predation, and plant dispersion through seeds consumption. ${ }^{1,4}$ Large and medium-sized mammals are very sensitive and intolerant to disturbance and indicators of the healthiness and integrity of ecosystem. ${ }^{4-6}$ Mammals also act as umbrella species because of their large area home range requirements and contribute to the conservation of other species. ${ }^{1,4}$

Large-sized animals are more vulnerable to local extinction than their small sized counterparts because of their large home-range requirements, naturally low population densities, and are typically favored targets for hunting. ${ }^{2,4}$ It is also very difficult to study mammals because most of the species are cryptic, occur at low densities, nocturnal, or inherently difficult to observe. ${ }^{1}$ Recently, numerous anthropogenic factors have promoted habitat loss and fragmentation, and the decline and losses of global mammalian biodiversity., ${ }^{3,7}$, Habitat destruction has also caused some large sized predatory species to venture into human settlement areas, and pose risks to humans and themselves. ${ }^{1}$ Cardillo et al. ${ }^{9}$ have predicted more rapid loss of large mammals of the world in the near future. The reduction of small and medium-sized mammals may be less evident but equal to or greater than those of large size.

Mammal inventories are tremendously vital to improve our understanding of their geographical distribution. ${ }^{10}$ The ecological
Volume 4 Issue 2 - 2019

\author{
Kabeta Legese,' Afework Bekele, ${ }^{2}$ Seyoum \\ Kiros' \\ 'Department of Biology, Wolkite University, Ethiopia \\ 2Department of Zoological Science, Addis Ababa University, \\ Ethiopia
}

Correspondence: Kabeta Legese, Department of Biology, Wolkite University, Ethiopia, Tell+25 I9|2360046, Email kabet12@gmail.com

Received: February 12, 2019| Published: March 18, 2019 relevance of mammals, shortage of ecological data and increased human threats make the matter very essential and necessary to evaluate their current conservation status. ${ }^{7,11}$ The absence and rarity of these mammals in a given ecosystem have severe consequences in the structure, composition and diversity of forests. ${ }^{3}$ Hence, surveys of mammalian diversity, abundance and habitat conditions of a particular ecosystem is the first step for conservation action and provide information to establish appropriate conservation strategies. ${ }^{6}$ Understanding of which and how mammalian species persist in disturbed fragments may also indicate the minimum requirements of the species and might contribute to their conservation. ${ }^{8}$

There are several survey methodologies currently in use for the inventory of medium and large-sized mammals. The most commonly used methods are footprint identification, line transect censuses and camera traps. ${ }^{10,12}$ Transect sampling is a widely used survey technique, and considered volunteer-friendly. ${ }^{10}$ Camera-trapping is comparatively a new and most effective method for the inventorying of cryptic mammals. ${ }^{12}$ Mammals of Ethiopia are under progressive studies, but the diversity and conservation status of mammalian species outside protected areas are poorly known., ${ }^{5,6}$ However, the study of mammals in unprotected areas is equally important even more because of the huge anthropogenic pressures they absorb from their surrounding environments. Wabe forest is one the current an unprotected area that has been fragmented into numerous patches due to extensive anthropogenic pressures. It is a heavily exploited and perhaps in virtue of total destruction if conservation actions are not in place in the future. This ecosystem was hypothesized to contain some medium and large-sized mammal species in its forest patch. Like most of unprotected areas of the country, there is no information available 
about the mammal species diversity, abundance and the level of threat on this disturbed ecosystem. Therefore, the aim of this study was to survey and document the species composition of medium and largesized mammals and the prevailing anthropogenic threats to wildlife in Wabe Forest fragments.

\section{Materials and methods}

\section{Description of the study area}

The study was conducted in Wabe Forest located near to Wolkite town of Gurage Zone, southern Ethiopia $178 \mathrm{~km}$ from Addis Ababa on the way to Jimma. There are numerous fragmented habitats around the town particularly along Wabe River basin that adjoins Gibe River Wabe River catchment is a sub-catchment of the Omo-Gibe which is located between $08^{\circ} 21^{\prime} 30^{\prime \prime}$ and $08^{\circ} 30^{\prime} 00^{\prime \prime} \mathrm{N}$ and $38^{\circ} 05^{\prime} 40^{\prime \prime}$ and $37^{\circ} 49^{\prime} 00^{\prime \prime} \mathrm{E}$ (Figure 1). The area is located within altitudinal range of 1050 to $1835 \mathrm{~m}$. a. s. 1. The catchment covers a drainage area of about $1860 \mathrm{~km}^{2} .{ }^{13}$ The current study do not cover the entire catchment, but limited to the fragment of forest habitat in the vicinity of Wolkite town

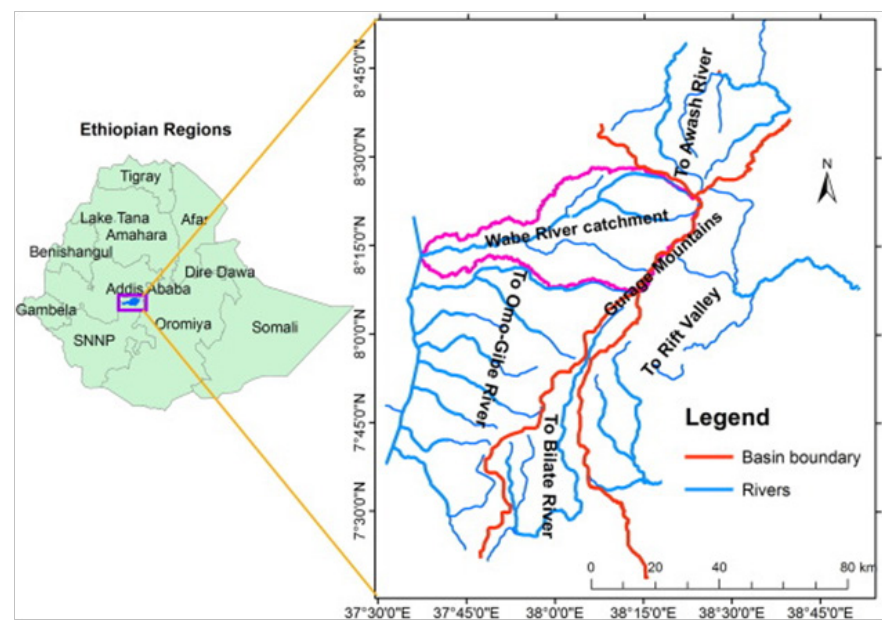

Figure I Map of Wabe River catchment (Source: Sahle et al. ${ }^{14}$ ).

The annual rainfall in the area is high, and the mean value ranges between 1100 to $1320 \mathrm{~mm} / \mathrm{yr}$ with low inter-annual variation..$^{13,15}$ The rainfall in the area is bimodal. The dry season includes December, January, February and March and the rainy season includes June, July and August. ${ }^{15}$ The maximum temperature ranges from $20^{\circ} \mathrm{C}$ (in the wet season) to $39^{\circ} \mathrm{C}$ (in the dry season), while the minimum temperature is in the range 0 to $19^{\circ} \mathrm{C}$. The average temperature is $18^{\circ} \mathrm{C} .{ }^{13}$

\section{Data collection}

A pilot survey was conducted to explore the accessibility and habitat characteristics of the study sites. The study area was then stratified into three blocks of fragments in reference to the Wabe River. The eastern side of the river is well vegetated and mainly considered as the natural forest habitat type: the western side of the river is separated by the road into south and northern sections. The study blocks were finally grouped into three major habitat types (human plantation, scrubland and natural forest) on the basis of vegetation cover. ${ }^{3} \mathrm{~A}$ total of 33 line transects ( 3 from human plantation, 18 from scrublands and 12 from natural forest) with a length of 1 to $1.5 \mathrm{~km}$ were established to conduct the surveys. The total number, length and distance and width of line transects were determined by the size and topography of the sites..$^{2,16}$
Diversity and threat data of mammals in the study site was collected from the established line transect in each habitat from April 2018 to May 2018. ${ }^{5}$ Direct and indirect observations of medium and large mammals were conducted along randomly selected transects (trails, footpaths and other access routes). Walking censuses were conducted along randomly selected transects (trails, footpaths and other access routes) and direct and indirect observations of mammals were recorded. Direct observation was made with the aid of binoculars, ${ }^{17,18}$ while evidence of tracks, scats, burrows, scratches, feeds, beds, calls were considered indirect observation. Indirect evidences are very useful when surveying animals that are naturally rare, elusive, found at low densities and difficult to capture repeatedly. ${ }^{16}$

Surveys were conducted twice when the animals are mostly active: in the morning (06:00 to 10:00 am) and late afternoon (16:00 to 18:30 $\mathrm{pm})$ in each transects. ${ }^{5}$ Species identification was made by using standardized field guides ${ }^{19,20}$ and from personal experiences. Evidence of illegal activities and recent human disturbances such as charcoal production, hunting, farming and logging activities in the area were also anecdotally recorded. ${ }^{3,18}$ Similarly, local people were anecdotally interviewed on the species present and their thought on the threats and conservation of the study site and its mammals. Interview questions were supported with field guide photos and illustrations to ease the difficulty and extract reliable information from the informants. ${ }^{3,21}$

\section{Data analysis}

Collected data were organized and entered into a worksheet for the analysis. Shannon-Weiner diversity index $\left(\mathrm{H}^{\prime}\right)$ was used to analyze the species diversity of mammals. ${ }^{22}$ Shannon-Weiner diversity index $\left(\mathrm{H}^{\prime}\right)$ was computed by the formula: $\mathrm{H}^{\prime}=-\left[\sum \mathrm{PilnPi}\right]$ Where, $\mathrm{Pi}$ is the proportion of each species in the sample: InPi is natural logarithm of this proportion.

Species evenness, which represents the distributional patterns of mammals, was evaluated using Shannon-Weiner evenness index (E). $\mathbf{E}=\mathbf{H}^{\prime}$ / Hmax Where, H' is Shannon-Weiner diversity index and Hmax $=\operatorname{lns}$, is natural logarithm of total number of species in each habitat. Simpson similarity index (SI) was also computed to assess the similarity among and between the study habitats with reference to the composition of species. $S I=2 C / I+I I$ Where: $\mathrm{C}=$ the number of common species to the habitats $\mathrm{I}=$ the number of species in habitat one II $=$ the number of species in habitat two.

The relative abundance index of species (RAI) was calculated by dividing the number of records of each species by the total number of records of all species. The abundance of observed mammals was categorized as common if they were seen during all of the surveys, uncommon if they were seen in more than half of the surveys, and rare if seen less than half of the surveys. ${ }^{5}$ Interview surveys were presented descriptively because of the small size of study participants.

\section{Results}

\section{Species composition}

A total of 1391 observations of 12 species of medium and largesized mammals belonging to seven families and five orders were recorded. Order Primates was the most abundant order followed by Artiodactyla, whereas Carnivora were the order less represented in the study area. At family level, Cercopithecidae, Bovidae and Suidae were the dominant families:while Hyeniadea, Mustelidae and Hystricidae were the less represented families in the study area 
(Table 1). Interview results revealed that African Hippopotamus (Hippopotamus amphibus) has been an inhabitant of the area before human pressure has forced them to migrate to downstream areas. Respondents also claimed that this animal still visits the area very rarely during the food shortage time in its current habitat. However, it is very difficult to assume this mammal inhabits the area considering the current anthropization.

\section{Distributional patterns and abundance}

The distributional pattern of mammals in the current study area varied across the study habitats. High number of species was observed in the scrub lands ( 8 species) followed by natural forest ( 7 species), and plantations ( 2 species). However, natural forest harbored more mammalian records than the other three habitats. Majority of the species $(76.5 \%)$ were observed at least in two of the three habitats, but certain species were also limited to specific habitat type. Specifically, bohor reedbuck (Redunca redunca) and guereza (Colobus guereza) were only recorded from natural forest. Similarly, crested porcupine (Hytrix cristata) and bush pig (Pontamochoreus larvatus) were exclusive to scrublands (Table 2).

Table I Species composition of mammals in Wabe Forest fragments

\begin{tabular}{llllll}
\hline Order & Family & Scientific name & Common name & Local name & ID Evidences \\
\hline Artiodactyla & Suidae & Phacochoerus aethiopicus & Warthog & Karkaro & Visual/Scant \\
& & Pontamochoreus larvatus & Bush pig & Asema & Scratches \\
& Bovidae & Ourebia ourebi & Oribi & Midako & Visual \\
& & Redunca redunca & Bohor reedbuck & Dikula & Visual \\
& & Sylvicapra grimmia & Common duiker & Midako & Visual \\
Primates & Cercopithecidae & Papio Anubis & Olive baboon & Zingero & Visual \\
& & Colobus guereza & Guereza & Gureza & Visual \\
& & Chlorocebus aethiops & Vervet monkey & Tota & Visual \\
Carnivora & Hyeaniadea & Crocuta crocuta & Spotted hyena & Jib & Foot print/Scat \\
& Mustelidae & Mellivora capensis & Honey badger & Kafo dafi & Carcass \\
Tubulidentata & Orycteropodidae & Orycteropus afer & Aardvark & Awaldigessa & Holes \\
Rodentia & Hystricidae & Hytrix cristata & Porcurpine & Jart & Spines/Scant \\
\hline
\end{tabular}

Table 2 Mammalian species distribution occurrence and abundance in Wabe Forest fragments

\begin{tabular}{|c|c|c|c|c|c|c|}
\hline \multirow{2}{*}{ Common name } & \multirow{2}{*}{ Scientific name } & \multirow{2}{*}{ Occurrence } & \multicolumn{4}{|c|}{ Habitat types } \\
\hline & & & Plantation & Scrubland & Natural forest & RAI \\
\hline Warthog & Phacochoerus aethiopicus & Uncommon & - & 25 & 8 & 2.3 \\
\hline Bush pig & Pontamochoreus larvatus & Rare & - & 7 & - & 0.5 \\
\hline Oribi & Ourebia ourebi & Uncommon & 2 & 4 & 4 & 0.7 \\
\hline Olive baboon & Papio Anubis & Uncommon & - & - & 30 & 2.1 \\
\hline Guereza & Colobus guereza & Uncommon & - & - & III & 8.0 \\
\hline Bohor reedbuck & Redunca redunca & Uncommon & - & - & 22 & 1.6 \\
\hline Spotted hyena & Crocuta crocuta & Rare & - & 6 & 1 & 0.5 \\
\hline Aardvark & Orycteropus afer & Uncommon & - & 37 & - & 2.6 \\
\hline Vervet monkey & Chlorocebus aethiops & Common & - & II & 116 & 9.0 \\
\hline Honey badger & Mellivora capensis & Rare & - & I & - & - \\
\hline Crested porcurpine & Hytrix cristata & Rare & - & 5 & - & 0.4 \\
\hline Common duiker & Sylvicapra grimmia & Rare & 2 & 4 & - & 0.4 \\
\hline
\end{tabular}

Among the 12 species of mammals, vervet monkey (Chlorocebus aethiops) was the dominant mammalian species followed by guereza (C. guereza), with common duiker (Sylvicapra grimmia), spotted hyena (Crocuta crocuta) and bush pig (Pontamochoreus larvatus) the less common species. Spotted hyena, aardvark (Orycteropus afer), honey badger (Mellivora capensis) and bush pig (P. larvatus) were exclusively identified from indirect evidences. The occurrence of mammals in the present study was also categorized based on their encounter rate during the study duration. According this rate, more than half of the species were uncommon. Only vervet monkey $(C$. aethiops) was considered common, while the remaining mammals were rare.

\section{Species diversity and evenness}

The highest diversity of mammals was recorded from scrublands and the less was from human plantations area. Similarly, mammals were more evenly distributed in scrublands than forested areas (Table 3). Simpson Similarity Index value also showed a considerable overlap of species $(\mathrm{SI}=0.58)$ between scrublands and forest habitats. 
Table 3 Species diversity and evenness of Wabe Forest

\begin{tabular}{llllll}
\hline Habitat types & $\begin{array}{l}\text { No. of } \\
\text { observations }\end{array}$ & $\begin{array}{l}\text { No. of } \\
\text { species }\end{array}$ & H' & Hmax & E \\
\hline Human plantation & 4 & 2 & 0.69 & 0.69 & 1.00 \\
Forest & 292 & 7 & 1.13 & 1.94 & 0.58 \\
Scrub land & 99 & 8 & 1.71 & 2.07 & 0.82 \\
Total & $\mathbf{1 3 9 0}$ & $\mathbf{1 2}$ & - & - & - \\
\hline
\end{tabular}

\section{Major threats to mammals of wabe forest}

Field observations have showed that human activities have greatly influenced the diversity and abundance of mammals in the study area. There was an ongoing road construction bisecting the natural forest to shorten the distance between Wolkite University and Wolkite town. This construction activity has exposed a previously inaccessible portion of the forest for human exploitation and also disturbed the wildlife of the area. Moreover, mining of construction materials from different parts of this area have also fragmented the habitat, and greatly disturbed wildlife therein.

During the transect walk, evidences of illegal logging of trees for fuel wood, extraction of construction materials, grazing by livestock, human encroachment, extensive agricultural expansion and charcoal production were observed. People in the surrounding of the study area seemed to have unrestricted access to cut trees of their interest because it is a source of revenue generation for the poor. Extensive fuel wood harvest has been seen with the aid of donkey. These individuals and other local people in the study area were also continuously accompanied with groups of domestic dogs that may attack and disturb mammals in the study area. Clearing of natural trees for farming purposes and to replace them by exotic trees such as Eucalyptus species, and human encroachment were also observed in certain vacant areas between fragmented habitats (see supplementary materials).

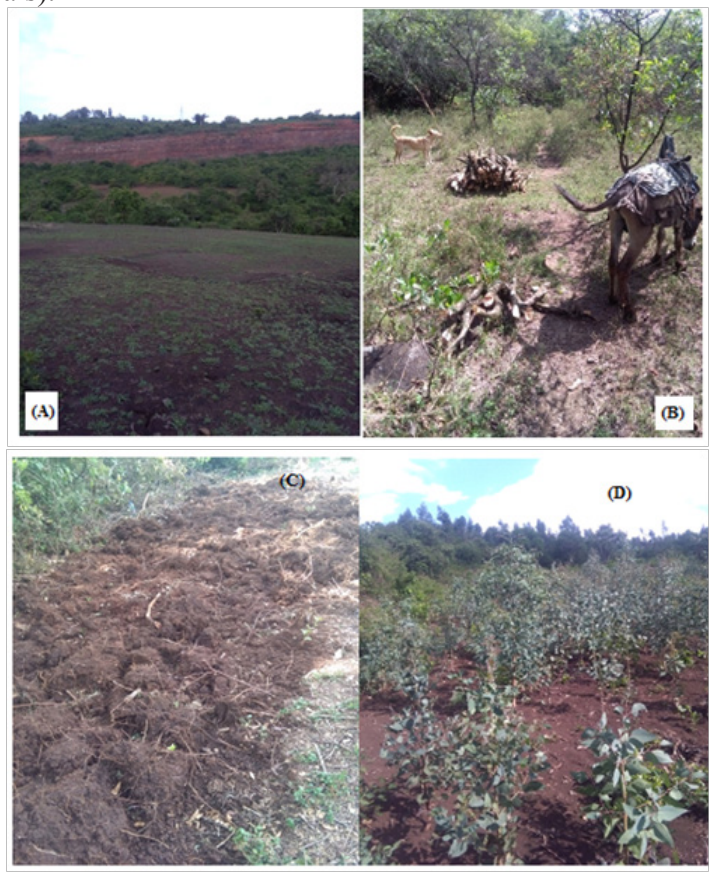

Supplementary Figure Major threats to mammals of Wabe Forest.

(A) Mining of construction materials, (B) logging for fuel wood with donkey, (C) forest clearing for agricultural land, and (D) replacement of natural forest by Eucalyptus trees (Photo by: Kabeta L.).

\section{Anecdotal interview results}

Anecdotal interview survey of the local people on their knowledge and attitudes towards the wildlife, their habitat conservation and threats to the study habitat were employed to seven individuals available in the study area during the study period. The study participants were two farmers, fuel wood exploiter and landowners in the study area, and a charcoal producer. All of them were males and had knowledge of the animals living in the area. They also showed positive attitudes for the conservation of the area.

Most of the study participants except the beneficiaries were angered by the lack of regulatory body of an excessive fuel wood exploitation and charcoal production from the forest, and showed interest to participate in the conservation of the area. Fuel wood exploiters expressed that the lack of job opportunity is the main reason that forced them to engage in this activity and the benefit they are obtaining from it is also not satisfying (25ETB per a donkey). All the study participants assumed that the government has the responsibility to ensure the protection of the habitat.

\section{Discussion}

The 12 species records of mammals during the present study gives a good picture of the mammal resources in Wabe Forest fragment. The mammalian diversity of the current study is very low compared to areas of different protection level across the country and elsewhere. ${ }^{5,23-26}$ But it is comparable to the report of Geleta \& Bekele ${ }^{3}$ from Wacha protected forest in the western Ethiopia. It is also similar to the work of Atnafu \& Yihune ${ }^{6}$ from communal forest of northern Ethiopia. The low species richness of mammals in the present study area might be associated with a limited survey period, variation in the size of the study areas, and severe habitat loss and fragmentation by various anthropogenic pressures.

Changes in habitat and landscape characteristics due to landuse change can have also a significant effect on species presence, abundance and distribution. ${ }^{27}$ Currently, fragmentation and habitat destruction are the two main driving factors of mammalian populations' decline. ${ }^{28}$ According to Turner ${ }^{29}$ small fragments often have fewer species recorded for the same effort of observation than large fragments or areas of continuous forest. This is due to the deleterious effects of human disturbance during and after deforestation, the reduction of population sizes, the reduction of immigration rates, the increases of forest edge effects, changes in community structure and the immigration of exotic species. Wabe Forest is an unprotected ecosystem that absorbs intense human pressure from its surrounding environments.

The current study also registered a few large-sized mammals. It is in contrast with the findings of several reports from different parts of the country. ${ }^{3,5,26}$ This finding is a characteristic of ecosystem that is under high level of severe threats. Large mammals are globally experiencing high population decline following anthropogenic disturbance due to their naturally low population densities, habitat fragmentation, over-exploitation and requirement of large area., ${ }^{4,930}$ They are also preferentially targeted by hunters. ${ }^{4}$ Probably, many of large mammals in this habitat also migrated to other habitats before their local extinction. This scenario is also witnessed by the downstream migration to Gibe Sheleko National Park claim of African hippopotamus (H. amphibius) by the local communities.

The distribution and habitat association of mammals are associated with vegetation cover, food and water availability in the area. ${ }^{5}$ Like 
most mammalian studies, the current study showed tendency of mammals to favor one habitat over the other following the change in the abundance and quality of resources. ${ }^{3,5,6,26,31}$ In the current study, scrublands have high species diversity of mammals. This finding is against most studies that reported high species diversity of mammals either in woodlands or forest habitats. ${ }^{3,17,26}$ This might be due to the difference in the habitat characteristic and the small size of the forest habitat of the current study site. The presence of indirect evidences of not sighted animals in the scrub lands may also increase the species diversity of this habitat and suggests the use of this habitat by these animals during the night time.

Most the mammal species surveyed in this study were recorded by direct observations. This might be linked to easy detection of animals due to the openness of the habitat which might have resulted from habitat loss and fragmentation. ${ }^{3}$ Vervet monkey (C. aethiopis) and guereza $(C$. guereza) were the most abundant mammals in the current study area in that order. Several studies have also reported similar abundance of primates from different parts of Ethiopia. ${ }^{3,5,24,26}$ This is perhaps due to the high reproductive successes, diversified foraging behavior and high tolerance level of primates to human disturbances. ${ }^{17}$ ${ }^{26}$ High species richness of these primates may be also associated with the wide distributional range of the species ${ }^{17}$ and their more adaptive nature to different habitats. ${ }^{5}$

Several studies from different parts of Ethiopia have also reported the abundance of these primates in riverine and woody habitats. ${ }^{26}$ In the current study, these two primates were also abundant in riverine forests. Vervet monkey (C. aethiopis) was mostly seen at the edge of the forest closer to the river forests and at the center of the natural forest. Similar result is reported by Chanie \& Yirga. ${ }^{17}$ The presence of this species at the edge of the riverine forest might be associated with a system of feeding on crops from shorter distance and easier sheltering when back off. In line with the finding of Fetene et al. ${ }^{32}$ and Geleta \& Bekele, ${ }^{3}$ guereza (C. guereza) largely selected riverine and large trees, but was totally absent in the scrublands. This is because riverine habitats are inaccessible to humans ${ }^{5}$ and harbor fresh grass and other leafy plants. ${ }^{26}$

The low diversity and abundance of mammals in human plantation area suggests that mammals prefer relatively less human disturbed areas. This might be due to the small proportion of sampling, and the dominance of homogenous plant species, Eucalyptus species that provide low foraging and protection opportunity for large mammals. ${ }^{3,26}$ The distribution and abundance of large carnivores were minimal. This might be associated with the high level of human interferences of the area and their nocturnal and cryptic behavior so that their presence could not be easily documented. ${ }^{3,5,17}$

The distribution and abundance of the Order Artiodactyla were ranked next to primates. This finding contrasts with the finding of Geleta and Bekele. ${ }^{3}$ This variation might be due to the difference in the habitat characteristics of the study areas. These mammals have cryptic and shy behavior and use inaccessible area when human interference is high and the open habitats when the disturbance of human is minimal. The greatest species similarity was observed between the scrublands and forest habitat. Several studies disagree with this finding. ${ }^{5,17}$ This is probably due to the proximity of these habitats to each other, difference in sampling efforts, and these animals use these habitats for foraging, and hiding from potential dangers interchangeably. More importantly, the resource and cover conditions of these two habitats are relatively closer to each other than to the human plantation.
Mammals of Wabe Forest are highly affected by several human induced factors such as forest clearing for farming, fuel wood exploitation, charcoal production, road construction and extraction of construction materials from the areas. This holds true for any human altered natural environment. ${ }^{3,33,34}$ Increasing global human population has been associated with extensive habitat disturbance related to changes in land cover, agriculture, rampant resource extraction, and extensive fragmentation of the remaining forests. ${ }^{33}$ Anthropogenic activities affect the interactions, distribution and diversity of species through habitat loss and modifications. ${ }^{35-37}$ Deforestation and habitat loss threaten mammals by decreasing area, connectivity, and fragment size, and increasing edge effects and number of fragments of the natural landscapes. ${ }^{8}$ These are closely linked to the expansion of roads and human settlements. Infrastructure developments are recently identified as the major threats to wildlife and their habitats. ${ }^{37}$ The ongoing road construction and extraction of construction materials in the current study area further fragment the habitats and are the potential threat to the existence of mammals in this ecosystem. Mammals inherently avoid the immediate vicinity of the road area and choose less disturbed areas due to road disorders such as artificial barriers, traffic danger, pollution, and noise. ${ }^{38}$ These roads also increase the accessibility of inaccessible areas for the local community. However,the large-scale effects of infrastructural developments still remain overlooked. ${ }^{37}$ Provision of fuel wood is an important ecosystem service of forests and woodlands. However, these may lead to their deterioration and degradation. ${ }^{7,34}$ Poor people use fuel wood and charcoal production as the best means of revenue generation. The proximity of Wolkite town to the forest might have increased the intensity of forest destruction for fuel wood, charcoal production and construction materials. Geleta $\&$ Bekele $^{3}$ have reported similar scenario from western Ethiopia.

Fuel wood exploiters and local communities visit the forest accompanied with dogs. Dogs are invasive species, and their presence in natural habitats adversely affects wildlife. All types of domestic dogs can interact with wildlife and have severe negative impacts on the biodiversity. The interaction between wildlife and dogs include predation, disturbance, disease transmission, competition, and hybridization. ${ }^{39-41}$ The distribution of dogs can significantly influence the space use of potential prey. ${ }^{42}$ The presence of human residents and hunters in protected areas facilitate dog occurrence. ${ }^{43}$ Livestock were also seen in all the habitats competing for food with mammalian species particularly ungulates. Gonfa et al., ${ }^{5}$ also reported adverse effects of livestock on wildlife of Dati Wolel National Park, western Ethiopia. In general, if these threats continue, there might be no more chance to see the present floras and faunas of the study area.

Anecdotally interviewed local people have knowledge and positive attitudes towards the mammals. They have also showed willingness to participate in the conservation of this ecosystem and the mammals it hosts if the government is to conserve the area. This is very important input for the conservation of the habitat. In contrast, Geleta \& Bekele $^{3}$ reported a negative attitude of local people toward wildlife from western Ethiopia. This variation might be due to differences in awareness and the level of wildlife associated to the numerical variation or costs of the study participants in the two studies.

\section{Conclusion and recommendations}

Wabe Forest harbors significant number of medium and largesized mammals under intense human pressures. However, most of them were largely confined to forest habitat in large number, and 
only with very few encounter in exotic forest plantation habitats. Most of the mammals in the study area are either disturbance tolerant or developed specific adaption to the prevailing conditions. The presences of disturbance tolerant and adaptive mammals in the study area suggest that this ecosystem is severely threatened and its resources are also severely depleted. Currently, fuel wood exploitation, charcoal production, road construction and mining of construction matters are identified anthropogenic factors that are threatening the forest fragments and mammalian species therein. Local people showed a good knowledge and attitudes for mammals and their conservation. This could be used as an opportunity and asset for the conservation of this ecosystem and its wildlife resources. An immediate conservation measures should be in place to retain these mammals with further detailed study, e.g. an alternative work opportunity should be created for fuel wood exploiters and charcoal producers to reduce the pressure from the habitat. Beside this, awareness should be created for the local people on the effects of forest destruction and domestic dogs on the wildlife.

\section{Acknowledgments}

None.

\section{Conflicts of interest}

Authors declare that there are no conflicts of interest.

\section{References}

1. Dirzo R, Mendoza E, Cachú Y, et al. Status of large and medium-sized mammals at JRBP. In: Chiariello N, editor. Jasper Ridge Biological Preserve State of the Preserve Assessment. Jasper Ridge Biological Preserve, USA: Stanford University; 2009.1-9.

2. Porras P, Vazquez L, Sarmiento-Aguilar R, et al. Influence of human activities on some medium and large-sized mammals' richness and abundance in the Lacandon Rainforest. $J$ Nature Conserv. 2016;34:7581 .

3. Geleta M, Bekele A. Survey of medium and large-sized mammals in Wacha Protected Forest, Western Ethiopia. J Agri Sci. 2016;6:71-79.

4. Carvalho D, Oliveira R, Pires S. Medium and large-sized mammals of the Reserva Ecolo' gica de Guapiac, u', Cachoeiras de Macacu, RJ. Biota Neotrop. 2014;14:1-9.

5. Gonfa R, Gadisa T, Habtamu T. The diversity, abundance and Habitat associations of medium and large-sized mammals in Dati Wolel National Park, western Ethiopia. Intl J Biodiv Conserv. 2015;7:112-118.

6. Atnafu G, Yihune M. Species composition and relative abundance of medium and large mammals in Mengaza communal forest, East Gojjam, Ethiopia. J Ecol Natural Environ. 2018;10:34-40.

7. Wuver A, Attuquayefio D. The Impact of Human Activities on Biodiversity Conservation in a Coastal Wetland in Ghana. WAJAE. 2006;9:1-14.

8. Bernardo V, Melo R. Assemblage of medium and large size mammals in an urban semi-deciduous seasonal forest fragment in Cerrado biome. Biota Neotrop. 2013;13:76-80.

9. Cardillo M, Mace M, Jones E, et al. Multiple causes of high extinction risk in large mammal species. Sciece. 2005:309:1239-1241.

10. Melo GL, Sponchiado J, Cáceres NC. Use of camera-traps in natural trails and shelters for the mammalian survey in the Atlantic Forest. Série Zool. 2012;102:88-94.
11. Eduardo A, Passamani M. Mammals of medium and large size in Santa Rita do Sapucaí, Minas Gerais, southeastern Brazil. Check List. 2009;5:399-404.

12. Roberts NJ. Investigation into survey techniques of large mammals:surveyor competence and camera-trapping vs. transectsampling. Biosci. Horizons. 2011;4:40-49.

13. Sahle M, Fürst C, Yeshitela K. Plant diversity analysis for conservation of Afromontane vegetation in socio-ecological mountain landscape of Gurage, South Central Ethiopia. Intl J Biodiv Conserv. 2018;10:161171.

14. Sahle M, Fürst C, Saito O, et al. Quantification and mapping of the supply of and demand for carbon storage and sequestration service in woody biomass and soil to mitigate climate change in the socioecological environment. Sci Total Environ. 2018;624:342-354.

15. Tilahun B, Abie K, Feyisa A, et al. Attitude and perceptions of local communities towards the conservation value of Gibe Sheleko National Park, Southwestern Ethiopia, Intl Sci E-J. 2016;3:65-77.

16. Chanie M, Yirga S. Diversity of medium and large-sized mammals in Borena-Sayint National Park, South Wollo, Ethiopia. Intl J Sci Basic Appl Res. 2014;15:95-106.

17. Bobo S, Kamgaing L, Ntumwel C, et al. Species richness, spatial distributions, and densities of large- and medium-sized mammals in the northern periphery of Boumba-bek National Park, southeastern Cameroon. African Study Monographs. 2014;49:91-114.

18. Owusu E, Ofor, B, Attuquayefio D . The secondary impact of mining on primates and other medium to large mammals in forest reserves in southwestern Ghana. The Extractive Indust Soci. 2018;5:114-121.

19. Chris, Stuart T. Field Guide to the Larger Mammals of Africa. 2nd edn Sruik publishers Ltd: 2000

20. Haltenorth T, Diller H. A Field Guide to Mammals of Africa including Madagascar. William Collins Sons and Co Ltd:1980.

21. Cáceres-Martnez C, Rincón A, González-Maya F. Terrestrial medium and large-sized mammal's diversity and activity patterns from Tamá National Natural Park and bu $\square$ er zone, Colombia. Therya. 2016;7:285-298.

22. Shannon E, Weiner N. The Mathematical Theory of Communication. University of Illinois press: 1949

23. Njoroge P, Yego R, Muchane M, et al. A survey of the large and medium sized mammals of Arawale National Reserve, Kenya. J East African Natural Hist. 2009;98:119-128.

24. Girma Z, Mamo Y, Erasdo M. Species composition, distribution and relative abundance of large mammals in and around Wondo Genet Forest Patch, Southern Ethiopia. Asian J Appl Sci. 2012;5:538-551.

25. Bene K, Bitty A, Bohoussou H, et al. Current conservation status of large mammals in Sime Darby oil palm concession in Liberia. Global Institute Res Edu. 2013;2:93-102.

26. Negeri D, Gadisa T, Habtamu T. The diversity, distribution and relative abundance of medium and large-sized mammals in Baroye controlled hunting area, Illubabor Zone, Southwest Ethiopia. Intl J Mol Evol Biodiv. 2015;5:1-9.

27. Andrade-Núñez M, Aide M. Effects of habitat and landscape characteristics on medium and large mammal species richness and composition in northern Uruguay. Zoologia. 2010;27:909-917.

28. Link A, Luna A, Alfonso F, et al. Initial effects of fragmentation on the density of three Neotropical primate species in two lowland forests of Colombia. Endangered Spp Res. 2010;13:41-50. 
29. Turner M. Species loss in fragments of tropical rainforest:a review of the evidence. J Appl Ecol. 1996;33:200-209.

30. Cardillo M. Biological determinants of extinction risk:why are smaller species less vulnerable? Animal Conserv. 2003;6:63-69.

31. Yimer D, Yirga S. Mammals of the Mazie National Park, Southern Nations, Nationalities and Peoples Regional State, Ethiopia. SINET:Ethio $J$ Sci. 2013;36:55-61.

32. Fetena A, Mengesha G, Beyera, T. Spatial distribution and habitat preferences of selected large mammalian species in the Nechisar National Park (NSNP), Ethiopia. Nature Sci. 2011;9:80-90.

33. Imre I, Derbowka A. Major threats facing terrestrial mammals in Canada. The Canadian Field-Naturalist. 2011;125:213-219.

34. Ndegwa G, Nehren U, Grüninger F, et al. Charcoal production through selective logging leads to degradation of dry woodlands:a case study from Mutomo District, Kenya. J Arid Land. 2016;8:618-631.

35. Collinge K. Spatial arrangement of habitat patches and corridors:clues form ecological field experiments. Landsc Urban Plan. 1998;42:157-168.

36. Kurki S, Nikula A, Helle P, et al. Abundances of red fox and pine marten in relation to the composition of boreal habitat. $J$ Animal Ecol. $1998 ; 67: 874-886$
37. Torres A, Jaeger J, Alonso J. Assessing large-scale wildlife responses to human infrastructure development. PNAS. 2016;113:8472-8477.

38. Saklaurs M, Baltmanis R. The Effect of roads on the movement of large and Meduim-sized mammals. Environ Climate Techno. 2015;14:23-29.

39. Doherty T, Dickman C, Glen A, et al. The global impacts of domestic dogs on threatened vertebrates. Biol Conserv. 2017;210:56-59.

40. Hughes J, Macdonald D. A review of the interactions between freeroaming domestic dogs and wildlife. Biol Conserv. 2013;157:341-351.

41. Wierzbowska I, Hędrzak M, Popczyk B, et al. Predation of wildlife by free-ranging domestic dogs in Polish hunting grounds and potential competition with the grey wolf. Biol Conserv. 2016;201:1-9.

42. Silva-Rodríguez E, Sieving K. Domestic dogs shape the landscape-scale distribution of a threatened forest ungulate. Biol Conserv. 2012;150:103110 .

43. Lessa I, Guimarães T, Bergallo $\mathrm{H}$, et al. Domestic dogs in protected areas:a threat to Brazilian mammals? Natureza Conserv. 2016;14:46-56. 